\title{
Chapter 5 \\ The Future of Japanese Transnational Entrepreneurs in South East Asia
}

\subsection{Fostering the Next Generation of Japanese SIEEs}

As we close out this book, we would like to leave the reader with some thoughts and observations on the future of transnational entrepreneurship in South East Asia from a Japanese perspective. We will begin by highlighting some new directions for Japanese HRM, education, both entrepreneurship and career education, some recommendations for becoming a SIEE and advice on setting up a business in South East Asia.

\subsubsection{New Directions for Japanese HRM}

\section{Recognize the Diversity Provided Through Gap Years}

- Offer gap years to new employees before they take up position

- Do not discriminate against students who have had gap years in evaluation system.

Our study found that engaging in a gap year, whether that be between studies or as part of a career-break, this valuable time allowed the individual to engage in personal growth and skills development. Not only do individuals gain knowledge but they also gain emotional intelligence and maturity, which helps them to make informed decision. A gap year fosters curiosity which is an important component when considering opportunity recognition. Therefore, it can be helpful for those transitioning in their career and considering working for themselves.

During this time a potential SIEE or company employee can engage in self-development as they 'find' themselves (Nieman 2010). The benefits of a gap year are well documented in literature outside Asia; therefore it would be an 
interesting area for future research within the region (Martin 2010; Heath 2007; Jones 2004; Birch and Miller 2007). We argue that one major benefit of a gap year is that they help an individual acquire soft skills. Exposure to soft skills helps to enhance career maturity and self-efficacy (Miles 2015). Naturally, a gap year also has its disadvantages. There is the emotional stress of being separated from friends and family, the feeling of loneliness, the financial burden and if not prepared properly, the lack of routine and a lack in a sense of purpose.

However, we argue that the advantages outweigh the disadvantages as Super (1990) and Super and Hall (1978) argue that that career maturity is associated with developing competencies in six areas, namely, knowledge of careers, knowledge of work environments, knowledge of preferred occupational group, planfulness, decision-making and accessing resources available for exploration and all these are fostered during the gap year process. Indecision is often seen as negative as it is thought to inhibit progression and development yet, we argue that this time of exploration is actually a time when an individual can negotiate their identity and gain new knowledge. As such, we would recommend that companies offer gap years to their new recruits before they take up their positions. In addition, we would hope that companies refrain from discriminating against potential employees who have had a gap year or 'time out' from their studies and embrace them on their soft skills, potential and maturity as well as their hard skills.

\section{Work-Life Balance}

The term work-life balance (WLB) in Japan has been a buzz word for the past 5 years and shows no sign of being given any less attention. It is at the forefront of the agenda for workplace reform, particularly in light of negative stories connected to overwork, worker depression and suicide and issues in family structure. Having a WLB does not just mean having time outside of work to relax, but it also implies the need to use time not in the workplace to build life experiences. It is through various experiences such as travel, time with family and friends, visits to new places and experiencing new things that help an individual to grow. Therefore, the promotion of the professional development benefits of WLB should not be ignored. Employees who achieve work-life balance have the potential to be more creative, happier and healthier and less burnt out. Time with family can often be extremely motivating and can ignite an individual to push themselves further. All of the SIEEs we interviewed stated they felt a different sense of duty and priority when they had children, thus if employees are able to spend more time with their children, they may grow professionally, too. For many SIEEs, experiences they have outside work during this WLB time are instrumental in their decision to become entrepreneurs. Similarly, we would like to suggest that companies offer sabbatical leave for travel for the same reason; it is through exposure to overseas that many SIEEs make the decision to leave Japan and set up their own businesses.

\section{Development of Specialists and Expand Mid-Career Track Job Market}

As we mentioned in Chap. 2 and will again later in this chapter, there is a need to differentiate between the development of specialists and generalists in Japan. We ascertain that although generalists are very successful as SIEEs, there are more 
opportunities that are often sought through being a specialist. Japan is quite rigid between specialist and generalist tracks and once an employee is in a particular track they are usually fixed there. We advocate for a more flexible mid-career track job market that would allow generalists to move to specialist track and vice versa without discrimination. If there was an interchangeable system, employees would have more flexibility and mobility. Thus, with this increased experience, an individual may spot an opportunity they could exploit for entrepreneurship. Increased exposure to various experiences is the key.

\section{Early Selection of Global Personnel}

Again, as touched upon in Chap. 2, what is a kokusai-jin or global ginzai? How to we ascertain if a Japanese person is global or has the potential to be global personnel? More often than not, employees must wait until their mid-career to be given the opportunity for global assignments or relocation. In this way, students graduating from university with experience overseas, language ability and/or an international posture are often left frustrated as when they enter a company, they spend a lot of time as a generalist, getting to know the ins and outs of the company as opposed to getting stuck into engaging with foreign clients, and so on. We advocate that it is necessary to start developing global personnel at an earlier stage in their career. Send these motivated individuals overseas for the experience or to subsidiaries within Japan, to widen their experience. These experiences will surely trigger an entrepreneurial way of thinking in these individuals. These experiences will help potential SIEEs to be competitive and develop leadership experience. If a company can find talent early enough they can mentor these outstanding individuals and give them opportunities by spotting their potential. Of course, the negative aspect for the companies in this scenario is that after the exposure the employee would want to leave to further develop his/her career, but this is a chance to take for improving HRM in Japan. Competition can be good in this situation.

\section{Promotion of Women in the Workplace}

From our previous research on Japanese women working in the United Nations, we appreciate that it takes much time to strive for equal job opportunities for women which is why we need to be patient. However, companies need to be encouraging women who want to break boundaries, be entrepreneurial.

There are three main ways that women can be better supported: (1) The development of an in-company and/or outside company mentoring system to give women access to role models. (2) opportunities to engage in networking events to increase their exposure and confidence; (3) more flexibility.

As we have seen in our study, many women seek out other entrepreneurs for support and advice but this should be supported and happening in companies, too. If a company provides better mentoring systems from when women join the company, they are likely to gain more experience, confidence and have more potential to take the step to become an SIEE. Similarly, women need more time to engage in networking but with family commitments this is often disregarded as attending post-work networking parties can be seen as frivolous or difficult to manage with childrearing duties. Additionally, organizers of such networking 
events should also vary the time that they take place to make them easier for more women to attend. Finally, companies need to be more flexible toward women in the workplace; allowing them the same opportunities for promotion and advancement, regardless of whether or not they have children or have taken maternity leave. They should be afforded equal opportunity for promotion, overseas assignments and such, all experiences that will lead to changes in their motivation, mindset, knowledge and development of networks; the antecedents of entrepreneurship opportunity recognition. For example, women should also be encouraged to see the benefits of life overseas with children, particularly small children, as many countries have childcare systems that are more advanced than Japan, which make it surprisingly easy to balance work and life. There are laws in Japan, such as parental leave, to encourage women in the workplace and to help them balance work life and childrearing; however, they are not always enforced.

\section{Supporting Employees to be Entrepreneurial}

A number of SIEEs in this study were encouraged to be entrepreneurial through their first workplace. Employers should provide opportunities for employees to develop new skills through entrepreneurial projects. Ways that employees can do this include asking them to come up with new ideas for products, services and ways of doing something in the company as this will encourage entrepreneurial, innovative and creative thinking. For those not in managerial positions, let them lead a team or put them in charge of a project. Ask them to set goals for the company. Encourage and motivate the employees by connecting their ideas and the development of their projects to financial or benefit rewards. In doing so, their intrinsic and extrinsic motivation will increase.

Additionally, managers in companies need to be more approachable when it comes to talking about outside work. A number of regular employees' surely harbor dreams of setting up their own company or run companies on the side but are reluctant to discuss this with their superiors for fear of being ridiculed or discriminated against; being accused that they are not committing to the company $100 \%$. But if employers opened up more and discussed these kinds of topics with their employees, they are not only supporting potential entrepreneurs but they are opening up lines of creativity in their employees. By engaging in these kinds of conversations managers have the added benefit of better understanding their employees to know what makes them tick and how they can be motivated which could lead to better levels of retention. Conversely, when employees experience the feeling of success and recognition of what it is to think entrepreneurially, this may inspire them to become an entrepreneur. 


\title{
5.1.2 New Directions for Entrepreneurship Education
}

\section{Constructivist Pedagogy and Approach}

Having reviewed the educational and life experiences of the Japanese SIEEs, we have formulated some recommendations for entrepreneurship education in Japan, yet we hope these suggestions may also be applicable in other contexts. We advocate for an integrated enterprise education framework that is grounded in social constructivist pedagogy. Using a constructivist model we can approach discrepancies and contradictions in the way a learner processes knowledge and how they filter and build knowledge and skills through their experiences. Essentially, we want learners to be able to connect the dots in their life, as we can see in the way the SIEEs have moved abroad and set up their businesses; encouraging them to be autonomous. Coupled with this, is the need to explore idea of the possible self as outlined in research by Birchley and McCasland (2016), which will help learners harness their understanding of identity and the role that it places in entrepreneurial mindset development. This role identity which is co-constructed will help students to visualize themselves as entrepreneurs and equip them with skills to navigate a globalized world.

Constructivism in education is an "approach to learning in which learners are provided with opportunities to construct their own sense of what is being learned by building internal connections or relationships among the ideas and facts being taught" (Borich and Tombari 1997). The learner builds on personal experience and is active and social in the learning experience. Scaffolding, collaborative group work and self-guided autonomous learning is the key, along with the additional element of peer review and evaluation.

\section{Box 1: Elements of Constructivist Pedagogy}

\author{
Knowledge construction \\ Learner-centered education \\ Collaborative learning \\ Project-based learning (PBL) \\ Critical and reflective thinking \\ Encouragement and development of creativity
}

A teacher working within a constructivist framework needs to be trained as the role differs from a more traditional style classroom. The teacher acts more like a facilitator and supporter of the student learning. Similarly, the student is not a passive receiver of knowledge but an active co-constructor of meaning and knowledge.

By educating Japanese students to be more entrepreneurial in general, this has greater benefits to a wider society, not just in the creation of new entrepreneurs. Entrepreneurial thinkers can contribute to job creation, economic success and societal challenges facing the country as they have the correct mindset to deal 


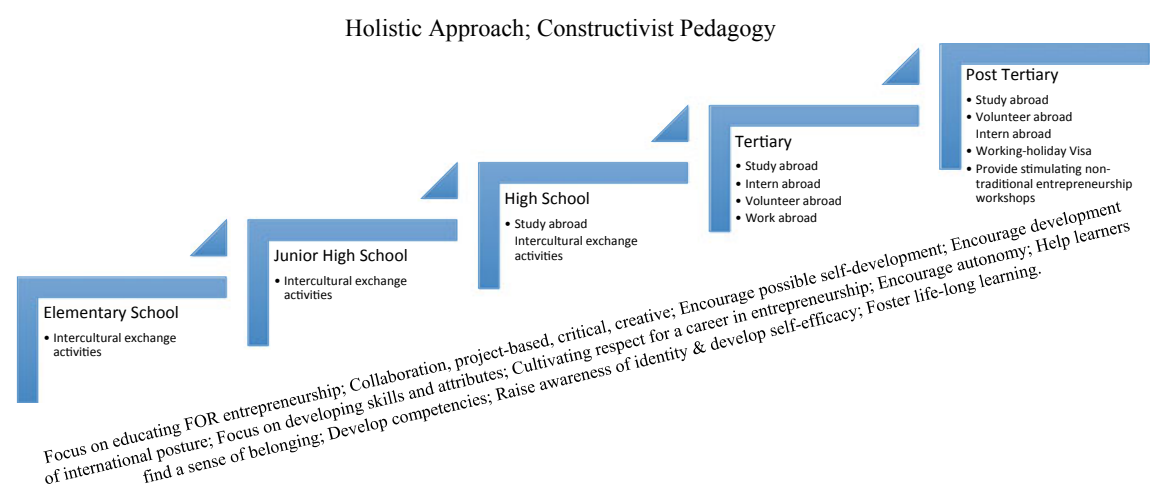

Fig. 5.1 A constructivist approach to entrepreneurship education in Japan

flexibly with the changing world. There needs to be a focus on classroom activities and assignments that encourage the learners to dig into their experiences and engage in activities that will develop entrepreneurial competencies. For example, the assignment could be to create something, and this requires an action such as working in a team or interacting outside the classroom environment, which in turn could develop a sense of self-efficacy. This pattern needs to be at the forefront of educator's minds. Figure 5.1 shows a diagram representation of potential Japanese entrepreneurship education.

\section{Project-Based Learning (PBL)}

We also advocate more project-based learning (PBL), which is recently gaining traction in Japanese universities but which could be more widely adopted earlier in the schooling system. Of course, learning by doing is already a powerful tool in business and enterprise education, however in PBL, the emphasis is not only on accomplishing an intellectual challenge but through collaboration, the students engage in authentic tasks, are able to reflect and develop roles in project management; all aspects are necessary for entrepreneurship. The student-centered nature of the delivery process of a PBL course helps students develop entrepreneurial behaviors and skills.

\section{Possible Selves}

Birchley and McCasland (2016) advocated bringing the notion of possible selves into the entrepreneurship classroom as it can help students consider what they might become, creating a link between cognition and motivation. Understanding one's possible self means to have "cognitive manifestations of enduring goals, aspirations, motives, fears, and threats" (Markus and Nurius 1986: 954). Awareness raising of the possible self has the potential to act as an incentive for future behavior as it can help us to see what the students aspire to and/or their not yet realized identities. Hoang and Gimeno (2015: 4) state that thinking about possible identities can "guide and motivate goal-oriented behavior, often to the extent that a possible role becomes an actual one." As such, we suggest it is necessary to consider what 
factors move individuals to become entrepreneurs and we should share them with our students. Through various inside and outside class activities, students can activate their schema about themselves to assist them in building cognitive maps that help them understand and process information.

\section{International Posture}

Another major concern for educators in Japan, but also in other countries we suspect, is the need to develop students with an international posture (IP). With regard to IP, in Japan, Yashima (2009) has conducted research on student's international orientation and willingness to communicate (WTC) and defines the construct of international posture as "to what extent learners are interested in or have more favorable attitudes towards foreign affairs... willingness to go overseas to stay or work, readiness to interact with intercultural partners, and...openness or a non-ethnocentric attitude toward different cultures, among others." Studies conclude that students who are aware of what it is to be international or global, tend to be highly motivated when studying language or seeking employment. This coupled with the positive selves concept outlined above are potentially very positive drivers of an entrepreneurial mindset, particularly in relation to SIEEs. Durand et al. (2018) argue that the extent to which students are able to visualize their possible selves in relation to being global can be an incentive for future behavior. By integrating ideas from the concepts of IP and possible selves, we can help learners examine their involvement with the international community, what if feels like to be an international person and/or business owner, helping them to develop mindsets and attributes that we see among the SIEEs in this study.

\section{Fostering an Entrepreneurial Mindset from Primary Age}

Through this study, we have become more convinced of the need to foster an entrepreneurial mindset from an early age. The reason for this is that when self-efficacy, the perception that an individual has of his/her ability (Bandura 1997), is high, the more likely it is that the individual will take action, therefore instilling this action-taking trigger in children will surely lead to more action taking in later life, and possibly less fear of to risk taking. Incorporating the development of self-efficacy in primary education will also help students to become lifelong learners as the child will see a world that is surrounding them, they can develop new perspectives and see and interact with the world differently, consequently being able to recognize opportunities presented to them, something that is at the core of entrepreneurship.

Undoubtedly, there are some critics of introducing such education to children at the primary level and these include financial and the perception of mindset training. Some educators and administrators feel that entrepreneurship education is too costly, financially and in terms of the time it takes to train teachers to deliver a thorough curriculum. Thus it is not seen as an integral part of the school or the student's journey through education, but as an appendage to the learning process. However, we argue that it should be integrated into the curriculum through a holistic, interdisciplinary approach. In Europe, in primary education, around 
Table 5.1 The ACRO model of entrepreneurship

\begin{tabular}{l|l}
\hline Attitudes & $\begin{array}{l}\text { Self-knowledge, belief, confidence, motivation, aspiration, determination, } \\
\text { competitiveness }\end{array}$ \\
\hline Creativity & $\begin{array}{l}\text { Problem-solving, lateral thinking, idea generation, spotting and creating } \\
\text { opportunities, innovation }\end{array}$ \\
\hline Relationships & $\begin{array}{l}\text { Working with others, managing difficult situations, negotiation, persuasion, } \\
\text { influence, presentation, communication }\end{array}$ \\
\hline Organization & $\begin{array}{l}\text { Planning, managing resources, decision making, researching and } \\
\text { understanding the environment, managing risk }\end{array}$ \\
\hline
\end{tabular}

Source Welsh Government

two-thirds of countries recognize entrepreneurship education and are horizontal or cross-curricular, forming a key component of the school's mission.

A model that could be adapted for use in the Japanese context is that of the Welsh Government, who identified the characteristics commonly displayed by Welsh entrepreneurs. Recognizing that entrepreneurship is a way of thinking that can be nurtured, the ACRO model was introduced to focus on the attitudes, skills and behaviors needed to enable young people to meet the needs of business in the twenty-first century. ACRO stands for attitudes, creativity, relationships, organization, and considers the everyday business tasks and underlying skills and attitudes of the entrepreneur (Table 5.1).

Introducing children to these behaviors from elementary school level helps to foster an entrepreneurial mindset in the individual from a critical period. Each subject in each section of the curriculum integrates the ACRO skills in some way through their lessons so that the students have multiple opportunities to engage with and practice using these entrepreneurial skills, while they are also developing self-efficacy.

\section{Creating a Culture of Entrepreneurship within the Institution}

As outlined briefly in Chap. 2, entrepreneurship education at the tertiary level is adopting approaches similar to the United States by utilizing consortia and business incubators; however, this is somewhat limited to more prestigious universities, with mid-rank and lower-rank universities not having the available funding to implement such programs; therefore, there needs to be a better system of industry-university collaboration in entrepreneurship and more access to incubators. Universities need to be more outward focused and responsive to the needs of industry when designing entrepreneurship programs.

However, we also advocate the need for entrepreneurship to be a more integral part of the university as a whole in order to create an entrepreneurial mindset and culture of the institution. One model that we feel Japanese universities could adopt is that of the University of Texas at Austin and their Blackstone LaunchPad. ${ }^{1}$ At the university, they take a holistic approach believing that entrepreneurship is for everyone. The LaunchPad is a cross-curricular, centralized hub on campus which

\footnotetext{
${ }^{1}$ https://ugs.utexas.edu/blackstone-launchpad.
} 
offers faculty, students and staff all the resources and support they need for idea generation and venture development. This includes workshops and networking events, free and confidential mentoring services, competitions for pitching and the SEAL Program; student entrepreneur acceleration and Launch program, which is a 9-week summer program to help students conceptualize and develop their new ventures. As an interdisciplinary and cross-campus service it highlights the way the university is fostering an entrepreneurial mindset and culture in the institution. Potential entrepreneurs work at their own pace, in the inclusive environment, which truly nurtures the individual. Regardless of how successful the entrepreneurs are through the hub, they have still developed an entrepreneurial mindset and skill set where they can take risks, be resourceful and can deal with failure.

\section{University Entrance Exam System}

As explained in Chap. 2 and by multiple scholars, Japanese university entrance systems are considered extremely ridged in that they funnel students into university through an examination that places value on rote memorization and not the twenty-first century skills we believe are necessary for successful integration into a global workforce. The Japanese government announced that the examinations will be reformed from 2020 in collaboration with private-sector organizations. In the previous job markets, rote memorization was highly valued among companies, as individuals were able to show retention skills but also malleability to fit into the company. However, in today's environment, where students are working with AI and other new technologies, and alongside a more internationalized workforce, the role and function of the worker is changing.

The new Center Test has been called the Daigaku Nyuugaku Kyotsu in an attempt to differentiate it from the traditional style test. The new test will examine critical thinking and students' ability to express themselves in the hope that they will be able to better adapt to the workplace and contribute to the economy and future of Japan. As well as open-ended questions, the test has reformed the English component; stating that students must show evidence of speaking ability by taking an external test provided by a private organization. Additionally, some universities are already adding multiple test components to cater for the changing nature of students, for example, presentation entry-route, where students give elevator pitch-type presentations as part of their entrance exam help to identify students who show the potential to be entrepreneurial, if they aren't already.

\section{International Exchange and Study Abroad Programs}

The Japanese government has been making great strides to increase the number of Japanese students studying abroad, and the number of non-Japanese students studying at Japanese institutions is also increasing. These are all part of the internationalization efforts outlined in Chap. 2. However, we feel that to help encourage entrepreneurship and the development of an entrepreneurial mindset among the next generation, although the traditional language-related study abroad programs are useful, the development and promotion of more innovate experiential learning programs abroad would be more impactful. 
There are three different approaches we would like to suggest: (1) Partner-university research and development projects; (2) experiential learning (EL) programs in emerging economies; and (3) overseas start-up internships.

By partner-university $R \& D$ projects, we mean that institutions can take advantage of the partnerships they already have to create joint research and development projects of a short- or long-term nature that has multicultural teams working together through a problem or project-based learning type pedagogy. For example, a group of students from one university could travel to the other and be put in teams with the partner institution to work on a project. This format could even be beneficial in a hackathon format, which could also be conducted online. These types of innovative exchange would add a new dimension to traditional study abroad offerings.

Experiential learning programs in emerging economies are a way for students to learn about their neighbors and better understand the needs and context of emerging economies. In addition, through this kind of activity, students can develop collaboration and negotiation techniques. These programs would be immersive and field-based. They combine classroom-based instruction with observations, research and data collection, and interaction with locals. The programs can be designed to fit with the student's major and thus they are not only learning more about their specialism, but they can also develop a critical understanding of the world.

Overseas start-up internships are becoming popular in Europe and North America. In these types of programs, students go overseas and intern within a start-up to experience the pace and culture of that kind of business. Of course, a barrier to Japanese young people may be language but as our book has illustrated there are many Japanese SIEEs working in South East Asia that also have Japanese as their working language; therefore students and universities should take the opportunity to seek out these kinds of companies and approach them for opportunities.

\section{Lifelong Learning and Exploration Stage Entrepreneurship Education}

Entrepreneurship is an important objective of lifelong learning as many of the SIEEs start their businesses after they have left formal education; therefore learning possibilities and courses should be available post-formal education. As such mentoring or tailor-made programs would be a natural fit for this demographic of learner where they could learn formal management practices but more importantly, can develop skills necessary for survival.

Examining the typical lifelong learning entrepreneurship programs offered in various communities in Tokyo, both through the government initiatives, private organizations and universities, it is clear to see they follow quite a traditional route and mid-career professionals are being offered opportunities to take foreign-MBA programs to help them advance to entrepreneurship. Yet, we believe that while these could be useful, there is a need to find an educational pedagogy and approach that is more impactful. Additionally, more attention should be paid to what are often termed non-traditional students; socio-economically disadvantaged, and/or those with a low educational level or non-traditional educational background. The idea 
that entrepreneurship can be an avenue for these individuals is positive, if we look at immigrant entrepreneurs, they are a prime example of how entrepreneurship can be life-changing regardless of background or socially economic situation. Similarly, graduates of vocational school also should be provided with more entrepreneurship education and training. It is in this area that local authorities can step in to support new initiatives. We wish to draw the reader's attention to the increased popularity and impact of the PopUp Business School that originated in the UK. Their approach is opposite to traditional approaches to business creation. They don't believe in business plans or loans and show participants of their workshops how to start a business without spending any money. Data from the PopUp Business School ${ }^{2}$ show that $30 \%$ of the people that come into their course start their business before the end of the workshop and $27 \%$ make their first sale within the first week. We advocate that although it goes somewhat against the culture of Japan and entrepreneurship education currently focused on the target group of mid-career potential entrepreneurs, if this radical approach was adopted it has the potential to open the field extensively and be highly impactful.

In general, in education, we argue that it is important to emphasize hybrid skills and soft skills development. Through developing knowledge of a particular subject, students also need to develop their transferable twenty-first century skills, and this may be possible through modular learning and pedagogies that support a social constructivist approach. The omnichannel nature of the world means that education should follow suit with a more flexible, fluid approach to providing education, both online and offline and through work placements, internships and other out of classroom experiences. This, combined with a focus on the development of soft skills will not only help to set students apart in a traditional recruitment market but will also help them be able to visualize themselves as potential entrepreneurs and give them varied experience and knowledge from which to draw on in the future; learners are building their social and human capital through these experiences.

\subsubsection{New Directions for Career Education}

We envisage a career education that would include a focus on developing competencies for the workplace that view career development as a journey as opposed to making a decision on one career destination. Within this context the student is surrounded by multiple stakeholders, not just a career advisor, but by classroom teachers, professional advisors, industry leaders and facilitators; a sophisticated integration of professionals. These people will help students to find multiple individual pathways and customize their develop plans in collaboration. The delivery of education will also be omnichannel to engage students and will take a heavily

\footnotetext{
${ }^{2}$ https://www.popupbusinessschool.co.uk/.
} 
Who am I? Awareness raisingPersonal attributes, Attitudes, What is work? What is a career? What are my strengths? What are my weaknesses? How do people change?

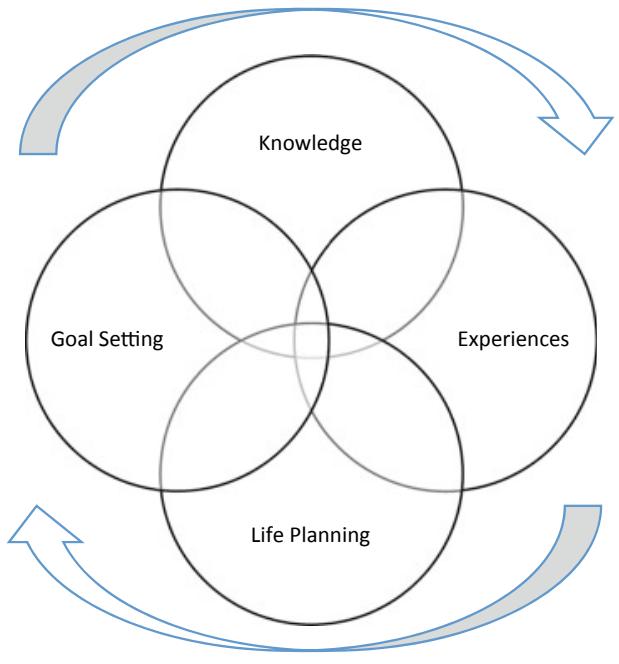

Who do I want to become?

Awareness raising What knowledge have I accumulated What options are available for me? What experiences make me who I am? How can I make things happen?

Fig. 5.2 A holistic approach to career education. Source Authors

holistic approach with students (and adults) co-constructing knowledge with facilitators and advisors to raise awareness of who they are and what they could become (Fig. 5.2).

\subsubsection{Reflections on Doing Business South East Asia}

As we have seen through this book, the barrier to entry in South East Asia for Japanese SIEEs is actually quite low compared to what we first envisaged. However, there are still some concerns about doing business in the region. Corruption, poor governance and the perceived instability of relations between China and the region and China and the United States has raised concerns. Additionally, although the tariffs imposed on goods imported within the region are zero, there are a number of non-tariff barriers that are still in place that require negotiation. Therefore as has been the case with the European Union, countries in ASEAN will have to find a consensus on issues that affect joint trade and industry, which in turn affects SIEEs. Three more areas of concern are language, adapting to new cultures, and finding and managing local talent. The first two issues are usually addressed by the SIEEs through joining language classes and becoming more embedded in their communities post-arrival. The third issue remains a major concern for the SIEEs. The key we feel would be harnessing the power of the millennial with value-driven propositions.

Conversely, the labor force is one of the biggest benefits to doing business in South East Asia. The middle-class growth rate is high and birth rate is generally 
Table 5.2 Summary of observations

\begin{tabular}{|c|c|}
\hline - Country & - Observations \\
\hline - Cambodia & $\begin{array}{l}\text { - Low barrier to entry, strong signs of growth, whole country is open for } \\
\text { business, strong support from the government, friendly relations with Japan. } \\
\text { The main business language is English which makes it more accessible and } \\
\text { the US dollar is used as the primary currency for business }\end{array}$ \\
\hline - Myanmar & $\begin{array}{l}\text { - Low barrier to entry but somewhat unstable politically, growing income } \\
\text { per capita, most new smaller companies can piggyback off larger companies, } \\
\text { opportunities available, friendly relations with Japan }\end{array}$ \\
\hline $\begin{array}{l}\text { - Vietnam } \\
\text { (Hanoi) }\end{array}$ & $\begin{array}{l}\text { Driven by HCM City, still behind economically and lacks trained labor } \\
\text { force, conditional entrepreneurship in that it is driven by other areas not the } \\
\text { area itself, highly influenced by the political economy }\end{array}$ \\
\hline $\begin{array}{l}\cdot \text { Vietnam } \\
\cdot(\mathrm{HCM})\end{array}$ & $\begin{array}{l}\text { - Capitalist in comparison to Hanoi, many Japanese companies already } \\
\text { established, more driven and currently expanding more than Hanoi, strong } \\
\text { labor force, hungry and determined }\end{array}$ \\
\hline - Philippines & $\begin{array}{l}\text { - After the Durete regime seeking stability, life is improving, statistics are up } \\
\text { and there is a similar mentality to what is found in Latin countries, there is a } \\
\text { north-south divide and some areas where religion makes it very difficult to } \\
\text { engage with the country as a whole; however, in Manila, the political } \\
\text { leadership is now strong, there is an ease of entry for Japanese companies, } \\
\text { the language is English, so relatively accessible and the culture is open }\end{array}$ \\
\hline - Indonesia & $\begin{array}{l}\text { - Religious instability, vast country with huge potential and possibility but } \\
\text { barrier to entry is the highest among the countries visited. Entrepreneurs } \\
\text { need in-country support and collaboration to be successful, however, once } \\
\text { considered to be an 'insider' it is easy to live, many of the entrepreneurs feel } \\
\text { comfortable to live there and have a sense of acceptance but understanding } \\
\text { the religion and culture is necessary }\end{array}$ \\
\hline $\begin{array}{l}\cdot \text { China } \\
\text { (Shanghai) }\end{array}$ & $\begin{array}{l}\text { - Capitalist-driven, many Japanese companies already established, therefore } \\
\text { relatively low barrier to entry, however, concern about the government's } \\
\text { relation to Japan and the USA causes a high degree of political uncertainty }\end{array}$ \\
\hline - Hong Kong & $\begin{array}{l}\text { - Capitalist-driven, similar to Shanghai but some Japanese companies are } \\
\text { already withdrawing due to the political instability between Hong Kong and } \\
\text { Mainland China. Japanese entrepreneurs with small firms feel they can't } \\
\text { expand at the moment as many of them rely on business from larger } \\
\text { Japanese companies }\end{array}$ \\
\hline - Thailand & $\begin{array}{l}\text { - Many Japanese companies already in Thailand. Smaller firms rely on } \\
\text { business from larger firms, many companies are expanding, increase in the } \\
\text { ease of doing business in Thailand so lower barrier to entry, the Japanese } \\
\text { domestic market is small so Japanese entrepreneurs in Thailand do not only } \\
\text { focus on exporting or providing services to Japan, but do so domestically in } \\
\text { Thailand or to neighboring countries }\end{array}$ \\
\hline
\end{tabular}

Source Welsh Government

higher, too. It is likely that when children watch their parents move up the economic ladder and start businesses they are influenced by them and motivated to be successful in the same vein. There is a hunger and ambitious feeling among the millennial generation. In addition, technology and innovation is embraced in Asia and moves at a steady, if not relatively fast speed. Harnessing this rapid expansion will surely give SIEEs the edge (Table 5.2). 
Advice and Recommendations for Starting a Business in South East Asia With regard to doing business in South East Asia, we have some general recommendations. First, it is useful to have some initial experience in South East Asia before becoming an entrepreneur. Potential SIEEs should advantage of the travel and welfare system opportunities within the region and backpack, go on trade missions, join an entrepreneurship association trip to the region, but get an initial understanding of the target country. Secondly, they should consider the type of field they wish to enter. Many successful SIEEs run companies that either serve as a clear B2B market, or they use their networking skills and connections to develop a company that connects people and/or resources, either in the host country and/or with Japan. These companies include recruitment companies, real-estate companies, education-related enterprises or consulting and strategy development firms. Thirdly, understand that one of the biggest challenges in working in the region (which is also one its biggest advantages) is how to train and retain local labor through value-driven propositions. However, building a strong intercultural team that can help navigate cultural boundaries will be useful. It is important to understand the country, religion, culture, financing rules, and so on, as much as possible before entering the market as one can expect to spend at least 1 year building relationships and trust in the host country. However, as the SIEEs in this study illustrate, the move to become an SIEE can be lucrative and beneficial for not only the entrepreneur, his/her family but also the region as a whole.

\subsection{On Becoming a Self-initiated Expatriate Entrepreneur}

From our exploration of the entrepreneurs in this study, we would like to conclude with some advice and recommendations for those individuals who aspire to be transnational entrepreneurs. However, many of the following recommendations are also applicable to those wishing to become entrepreneurs in their home countries.

\subsubsection{Exploration Stage}

For those wishing to become a self-initiated expatriate entrepreneur, we suggest that the key to success is taking advantage of a wide range of opportunities presented during the exploration stage of one's life. At this time in one's life, between the ages of 18-25 people usually experience college life, their first job, exposure to overseas, they may experience loss or grief or start a relationship. All these opportunities provide experience; the experience helps to shape their motivation, increases their knowledge, crafts their mindset and is the first opportunity to start building robust networks. Both men and women tend to start their businesses before 40, which means the exploration stage and into the establishment stage is the key time for planning as they can learn about what types of work are available and what 
different careers are open to them. They are able to take into account their skills, interests and expectations for life. They may not yet be clear about the future but they are in a position to take risks and evaluate their options. Many students do not take such risks at this time of life and thus limit their option of seeing what is potentially available. Consequently, they limit their ability to perceive opportunity. This time of like is called 'exploration' and many choose to settle, maybe too soon and risk limiting their options in the future.

- Recommendation: Actually spend time exploring in the exploration stage of life. Take advantage of opportunities offered.

\subsubsection{Exposure to Overseas}

One key experience during the exploration stage is being exposed to what is outside one's home country. Whether that comes from taking part in a study abroad program, backpacking or travel for work or with family, the key timing of this exposure should not be underestimated. The opportunity to go overseas provides the individual with the strongest opportunity to reassess his/her identity and develop new mindsets. One of the main benefits of going abroad at this time gives the chance to leave one's comfort zone. Some of the basics of life, such as the ability to make friends, work part-time, have been established and can make one feel comfortable but it is when we are uncomfortable in unfamiliar situations that we learn the most. Through travel we can meet others who may hold different values and thus, this gives us an opportunity to reassess our own values. By navigating a new environment, we have the ability to face new challenges, grow stronger and understand our identity better.

Similarly, overcoming an obstacle during travel, such as a miscommunication, can help build confidence; it is a teachable moment that cannot always be provided in a classroom setting. The need to make a split second decision in a foreign country helps develops resilience and cultural sensitivity. And, as more and more jobs in the future require employees to be globalized, these skills, the ability to travel and process the world outside one's home country, can give individuals a competitive edge in the workplace. The need to make decisions on a daily basis when traveling and deal with the demands of a different life in unfamiliar surroundings can trigger a person's creativity, innovative-thinking and personal development.

- Recommendation: Travel during the exploration stage of life. 


\subsubsection{Family and Lifestyle Choices}

Whether or not to get married is often a major decision in the exploration or establishment phase of life. From our study, the trends appear to be that males get married in Japan and rely on the support of a trailing spouse as they set up their businesses. At times, the couples are often required to live apart from their children when schooling them, therefore this needs to be given consideration when embarking on an international career as a spouse or parent. On the other hand, women tend to remain single when they start their businesses. This trend of an independent single woman is in line with general trends around the world. Work is given priority over finding a partner and having children. For those couples who were both expatriate entrepreneurs, one couple met and married in Japan and they took a joint decision to move to Cambodia. This requires commitment on both people to navigate the new lifestyle and culture and the couple in this study prove to be a strong support for each other. The expatriate couple who met when they were both overseas has a similar support network and mentor relationship with each other. Even though they pursue different businesses they are able to share ideas with each other and can turn to each other when they may experience difficulty.

- Recommendation: Consider the complexities of a marriage in an international context.

Similarly, when couples who work overseas or who are considering working overseas have children, there are more factors to consider. The majority entrepreneurs with children in this study stated that when they had children, their priorities changed entirely, from the focus on the business to focusing on providing for their families. They became slightly more risk averse and became more concerned with how to educate their children.

It is common for expatriates who work overseas to educate their children through an international school system, whereby the child most likely studies for an international baccalaureate (IB). Unlike in many countries where the IB is highly regarded, the traditional Japanese schooling system and university entrance system in particular, does not yet know how to adequately process such qualifications, and thus it could be the case that Japanese students are discriminated against for having not graduated from a Japanese high school. With this knowledge, many self-initiated expatriate entrepreneurs choose to educate their high-school age children in Japan, which often means they are separated from their child for a number of years. This almost obsessive need to graduate from a Japanese high school graduation in order to enter a top Japanese university is unlikely to change unless the entire education system in Japan changes, or universities slowly become more globalized. In all the South East Asian countries we visited they all had some form of Japanese language education and many had a traditional school system that would run through elementary school or junior high school and this was deemed sufficient initially; however, to provide children with a strong Japanese background and to give them the option of entering university in Japan and working in Japan in 
the future returning to Japan at this key stage is vitally important. If a child is educated in an international school until high school, then the parents must decide whether to educate their child in a foreign university or return to Japan with the status of a 'returnee' (a label given to a child who did not go to high school in Japan). If a child went to an international junior high school, then the decision of whether to go to a Japanese high school or continue in an international school becomes extremely important. Finally, the cost of a child's education was also mentioned among the entrepreneurs as a possible area of concern. To educate in an international setting can be expensive (often for assigned expatriates, the company who sponsors their assignment provides an education subsidy for their children, but of course, as self-employed, entrepreneurs do not have this luxury) and the entrepreneur must carefully consider how to educate their children, in what setting? Home setting, international setting, local setting? At what stages? And how much the education choice will cost?

- Recommendation: Give due consideration to children's education in an overseas context.

The term expatriate guilt is common in the academic literature and in the mainstream discourse. The notion of guilt (often tied to responsibility) is a key part of life abroad. And even though working overseas may be seen as glamorous, risk-taking, adventurous by others, the expatriate him or herself can feel an enormous sense of guilt for the family and friends they have left at home. This sacrifice can put a huge psychological burden on the individual (and the family and friends who remain in the home country). One of the main sources of guilt for the self-initiated expatriates in our study was not being available to care for elderly relatives and with many populations experiencing an aging population trend. This situation will likely be similar for expatriate entrepreneurs from a variety of countries. There are ways to overcome such guilt. In our studies, some entrepreneurs were able to leave the care to other members of the family; some were told by their parents to pursue their dream and gave permission to travel and explore life overseas. Some have made a conscious decision about returning back to Japan when the time is necessary. In order to cope, developing strong support networks overseas is vital and by creating a 'family' overseas, in whatever form that might take, or by seeking out an experienced mentor, will not only be helpful for overcoming guilt but will also help to motivate and add to one's knowledge base.

- Recommendation: Give due consideration to expat guilt and the care of elderly relatives

There is a strong focus on the need to maintain a work-life balance in modern society. The narratives of the expatriates highlight how despite working for themselves, many of them still maintain their hobbies as a way to not only relax but also to build professional and social networks. For example, joining a tennis club or dancing group overseas can help forge links with the host community, build friendships and gain inside knowledge of the new culture. If the club is an 
expatriate organization, then this provides the entrepreneur with a valuable link to his/her home country. It is through these networks that expatriates can learn about industry trends and increase their business connections. It can give an individual a strong sense of belonging, helping to maintain their identity (and navigate multiple identities), gives a sense of purpose and common goal.

The focus on well-being and self-care is especially important for an entrepreneur. When an entrepreneur has found happiness in career, it is often at the expense of having their own personal, quality, time and narrowly avoiding burnout. As we saw in our study, a vast number of entrepreneurs blend their social and professional networks; thus they are enjoying both the social side of their life while engaging in business to some extent. If this can be balanced, then this could be thought of as the optimal work-life balance. The key appears to be able to schedule life appropriately, whether that may be scheduling a game of tennis, scheduling a father's meet-up group or scheduling a dance recital. Each entrepreneur finds his/her own balance point and engages with their hobbies, interests and friends to varying degrees based on what is necessary for them.

- Recommendation: Engage with your hobby/interests and find a personal worklife balance

After deciding to relocate overseas, it is essential to engage with the new host community to be able to make the most of the experience. Many of the Japanese SIEEs in this study engage with their host communities, however, some remain more closely aligned with or within what is sometimes termed the expat bubble. Community engagement is relational and occurs at a very local level of society. The process of engagement means developing mutual trust and respect and developing common goals. Through engaging with the community, the SIEE can take part in tasks such as designing or planning something new for the community or helping them overcome a particular problem. Particularly in the context of working within a developing economy, the SIEEs can help to develop resources for the community and contribute toward community development and sustainability while simultaneously developing cultural awareness, cultural knowledge and cultural skills; all components of intercultural competency.

Intercultural competence is often emphasized in relation to expatriate training because cross-cultural training is based on the assumption that intercultural competence can be learned and taught. Yet, as we can see through these entrepreneurs, they may not have been explicitly 'taught' how to engage with the host community yet through interactions, they can acquire new skills and information about their host culture to help them survive and thrive. Some entrepreneurs in this study have engaged so deeply with the community that one of them built roads and developed infrastructure for their local area, while others have helped improve the skill level of the labor force of the country. An SIEE can contribute in many ways, not just economically, but also with their time, attitude and behavior.

- Recommendation: Engage with the local culture and community as much as possible. 


\subsubsection{Workplace and Career Choices}

Our study found that the majority of entrepreneurs worked within a more generalist field as opposed to specialist, which is expected due to the Japanese education system. Thus, it is important for a potential entrepreneur to understand the difference between a specialist and generalist and be able to understand where their skills and experience lie, particularly what skills they can leverage in their future business. It is sometimes considered to be the ultimate career choice and one decision from which all future decisions will be related. Generalists tend to have a loosely defined role within a business, whereas a specialist has a more defined role. It is interesting to observe that the entrepreneurs in this study use their wide range of knowledge and experience to create organizations that are broad in nature. A generalist can typically see how to join the dots of a problem or process as they have a 'bigger picture' mentality. They value interconnectedness and can think outside-the-box. It is unsurprising then that, overall, generalists have many transferable skills, use effective communication strategies and tend to be considered good leaders and managers. This was evident through our interviews. We also observed that what we would that the term generalists show a high degree of flexibility, not just in their work pattern but also in their career. They are less restricted and more open to risk taking as they can better understand and assess the various elements at play in decision making.

That is not to say that a specialist would not make a successful SIEE, specialists are often better compensated for their work due to their specialized, niche knowledge. Especially in emerging economies, a specialist would likely be able to add value to their community as they could easily become the thought leader in their new context and as people tend to seek help from experts when experiencing a problem, an expert SIEE could have many advantages over generalists in the field. Being aware of one's skill set and understanding what you could potentially bring to the table as an SIEE, whether that be as a generalist or specialist is vitally important and part of identity formation.

- Recommendation: Understand the difference between a specialist and generalist and see where your skills and experience lie.

Another finding from analyzing the lived experiences of the SIEEs is that none of them seemed to visualize becoming an entrepreneur as a final destination of their career. It was something that emerged organically over time as they traveled through their career and it may not end up being the final leg of their career journey. For some people, a career is a destination and when reached, the goal and satisfaction is achieved. However, with the SIEEs, success and becoming an entrepreneur appear to be journeys and that, if we think of it in terms of Maslow's theory of motivation, self-actualization is the pinnacle of life and something that we continue traveling toward. The motivation to reach it is part of the challenge of life and this thought is always helping us to 'become' rather than be 'complete.' 
The journey from want to be entrepreneur to entrepreneur means to forge one's own path and realize that you are on a journey of discovery; a journey through which your mindset will alter, your knowledge will increase, your motivation will fluctuate, your identity will become contested but you will have a sense of autonomy, belonging, and be aware of your competencies. At the same time, as there is a general, what could be termed, visible career, that is the tangible path (formal steps, observed by outsiders), entrepreneurs also have an invisible (to outsiders) career, more akin to an internal career, a general understanding of where they want to go in life (and the subjective reading of that journey).

The SIEEs showed a strong ability to deal with uncertainty, a high degree of flexibility and a sense of openness. Most of them are continuing to expand their businesses organically based on the opportunities they recognize in their various contexts. The ability to think on their feet and be responsive to change is a key part of their journey as they encounter various twists and turns.

- Recommendation: Consider a Career to be a Journey, Not a Final Destination.

Despite not all SIEEs having a mentor in their first workplace, those that did often still had the same mentor later in life. A mentor in the first workplace can be a huge influence on someone's career; they can make or break a positive workplace experience. A mentor helps to nurture talent and can help retain new employees. They can have a positive effect on job satisfaction and performance. The SIEEs found that having someone initially believe in them gave them a degree of confidence to believe in themselves. Mentors also help to create and connect their mentees with an expansive network, which in some cases proved very useful when the SIEE was setting up his/her business overseas. Creating a multigenerational company culture was also helpful for the SIEEs as the ability to draw on others' knowledge and experience was useful when learning how to set up businesses. Psychologically, a mentor helps to reduce stress and anxiety. Some of the SIEEs used mentors in their first workplace to do this, but as they gained experience and moved their careers in a different direction, the emotional support was provided by their spouse.

When engaging with a mentor, the SIEEs need to be committed to expanding their knowledge and competencies and willing to ask for help. A small number of SIEEs in this study preferred to be more 'lone ranger' types and make decisions alone, based on their gut. However, those who sought the help of a mentor were open and receptive to new ideas and ways of doing things. Through their mentor relationships they were able to also improve their interpersonal communication skills.

- Recommendation: Seek out a mentor in the first workplace.

The importance of engaging in a form of professional development and having a positive attitude toward lifelong learning cannot be underestimated. All the SIEEs in the study are engaged in professional development of some kind. The most common form was to read books not only on business-related topics but also on 
topics outside their field of knowledge or comfort zone. In reading about different fields, they could expand their knowledge base, become motivated by different things and thus increase their ability to recognize opportunities.

The SIEEs also see value in continuing to travel abroad during the establishment phase of their career. Travel, as it did in the exploration stage, gives the entrepreneur new perspectives and new opportunities. It was cited as an important form of self-development.

Another interesting fact is that some SIEEs returned to Japan for more formalized, classroom-based or lecture-based seminars. With the world being even more interconnected online, professional development becomes easier. This will likely result in a decrease in the number of Japanese people returning to Japan to study as qualifications may be more widely available online. In addition, training mobility will likely increase across South East Asia with training becoming available in places such as Thailand, Shanghai, etc. These changes open up a new niche training market.

- Recommendation: Engage in continual professional development.

\subsubsection{Developing Self-efficacy}

Schein's work on the concept of a career anchor explains that a career anchor is an individual's self-concept of what they are good at, their motives and values and how they govern their work and career choices. After a few years of working, the SIEEs are able to reflect on their experiences and their anchors evolve. When an individual is better able to understand his/her own needs, they can understand the world, what kind of employee or leader they can be and how they can contribute to society. When engaging in entrepreneurship it is useful for the individual to think about what motivates him/her and to try to formalize that in a career anchor. A mentor may help to guide the development of an anchor but ultimately it is up to the individual to decide on his or her own. From these SIEEs, we could see that many of their career anchors were related to their understanding of 'self' and their ability to recognize their management competencies. Recently, there are many online tests one can do to determine their career anchor; however, it is possible to feel just an alignment to one or more of Schein's categories and traits; technical competence, managerial competence, autonomy/independence, security/stability, entrepreneurial creativity, service, challenge and lifestyle. For those potential entrepreneurs in their mid-to-late $20 \mathrm{~s}$, it is a good time to reevaluate one's career and reflect on workplace experience to date.

- Recommendation: Develop a career anchor.

Similar to having a career anchor that recognizes one's competencies, having an innate ability to believe in oneself and have passion are also the key to becoming a successful SIEE. All the SIEEs in this study exhibited a high degree of self-efficacy. 
If passion is defined as an intense positive feeling, a type of energy that helps give one a sense of meaning, then the SIEEs in this study exhibited a strong sense of passion for their work and careers. They have been able to find and harness their passion to gain success. The level of positivity among the SIEEs was extremely high and the majority exhibited no signs of fear or perceived lack of challenge, indicating that they had few emotional roadblocks at the time of interview. Undoubtedly, the SIEEs faced entering a new country with some trepidation yet, the challenge of succeeding in a brand new environment was motivation enough to overcome any fear.

\section{- Recommendation: Have passion and positivity.}

A great amount of effort, time and money has been poured into developing English language skills among Japanese young people as the skill will enable them to work efficiently on the world stage. While this, of course, is a valid assumption, we found that the majority of SIEEs we interviewed were not exceptional in terms of their level of English language proficiency. They had a rudimentary amount of English to function; however, they did not possess a sophisticated level of business English. What they did have was a high level of general communicative ability and well-developed soft skills. Therefore, we would urge potential SIEEs to work on developing their soft skills over language proficiency at the beginning stage. Once established, many of the SIEEs engage in host-country language classes, enrolling in Thai or Vietnamese, for example, or even studying these at university level and prioritizing them over English.

A basic to intermediate level of English proficiency, around the Common European Framework of Reference B1 level, which is considered to be a threshold level, appeared to be sufficient for our entrepreneurs to flourish. At this level they can understand points regarding family, work, school and leisure-related topics, can deal with most travel situations and describe their experiences, events, ambitions as well as options or plans in brief terms.

Soft skills, particularly professional soft skills such as critical and analytical thinking, teamwork and interpersonal skills, are vital. What is most important in the modern world of business is the ability to be fluent in work behavior; this focus on 'behavior' and being a 'cultural fit' means that it is no longer possible to be linguistically competent; intercultural communicative competence and highly developed soft skills are critical. Breaking down soft skills into two categories; process skills (communication, teamwork, etc.) and awareness skills (knowledge of contemporary issues, etc.), we can see that the SIEEs in this study possess ample amounts of both types. We also found that at the core of a successful businessperson is initiative. The SIEEs had the power or ability to begin and follow through with their plans; they showed a high degree of determination and ability to assess situations. We argue that the development of these skills is more pertinent than becoming proficient in English. Thus, we recommend that an individual focus on having as many life experiences, through which he/she can develop soft skills. 
- Recommendation: Develop soft skills over foreign language skills from the outset.

Through the research we could easily see how SIEEs were forced to negotiate their identity at different points in their career. Identity and the nexus and trade-off between distinctiveness and belonging as individuals seek to find optimal distinction is something that many people are not aware of. A lack of awareness that at times, we need to negotiate our identity in certain situations may lead to stress, confusion and negative feelings. As such, potential entrepreneurs need to be aware of how their identity may be contested and learn to deal with frustration that may arise from that situation.

It is important to realize that an individual is not only negotiating the way they see themselves but also how others perceive them; therefore, the conceptions of one's self-identity may limit them in business situations, particularly in relation to negotiation. Therefore, to raise awareness, it is important to engage in developing emotional awareness and mindfulness. A number of SIEEs stated that they are engaged in some form of mindfulness activity or engagement with their emotions or thoughts. It is useful to find ways to manage moods and emotions in oneself; for some SIEEs that meant engaging in their hobby or travel, for others it was getting out into nature to feel grounded. Practicing mindfulness helps one to become aware of the emotions and identities within ourselves. Engaging in mindfulness not only helps the mind to settle but also the body.

- Recommendation: Be aware that identity is negotiated and use tools such as mindfulness to help recognize identities and beliefs.

\subsubsection{Key Business Decisions}

For any budding entrepreneur, how to finance a project is often considered the biggest hurdle to overcome. For our study, we found that actually, for many of the SIEEs, they found that finance was actually a relatively low barrier to entry when entering an emerging economy market in South East Asia. This makes the region very accessible and the nature of an emerging economy means that the opportunities for growth are immense. Therefore, when deciding to set up a business, restricting oneself to their home market is slightly short sighted when financial gain could be achieved in a newer market at a lower entry cost.

In connection with funding, the majority of the SIEEs used their own funding or that of traditional investment procedures. Only one SIEE used crowdfunding. Crowdfunding and angel investment has become an important part of an entrepreneur's journey in other countries around the world, but is slow to take traction in Japan. This may be culturally-related, but the potential power of crowdfunding should not be ignored by potential SIEEs. Crowdfunding can provide the SIEE with access to capital at an early stage. It helps to hedge risk and is a useful initial 
marketing tool. By engaging with investors online in a relatively barrier-free environment, the entrepreneur is able to quickly build new partnerships, gain customers and build confidence in themselves as a business owner and their brand. Of course, this path is not always appropriate for everyone, as there is a risk of failure and letting your funders down. The SIEE may not meet the threshold required by the crowdfunding site and/or your concept is laid bare to competitors on a wide platform. However, we recommend that SIEEs explore how crowdfunding may appeal to them; particularly younger entrepreneurs may find the tool suitable for their needs and abilities. They are more technologically engaged generation who used to manipulate social media; thus crowdfunding and online engagement may seem like a natural path to funding.

Similarly, using social media, such as Instagram, Facebook, LINE and LinkedIn can also raise the profile of an entrepreneur. Creating an online brand and identity is important. The high-impact social entrepreneurs are savvy users of online tools to increase their connections not only in Japan but also in their host country and wider afield. For example, becoming a moderator of an online expatriate group can enable one to build connections and recognition quickly. Similarly, giving advice to other entrepreneurs or expatriates on online forums or career advice boards, and so on, helps to raise the visibility (and thus the potential client base) of the SIEEs.

- Recommendation: Realize that finance is a relatively low barrier to entry for setting up a business in South East Asia.

- Recommendation: Explore how crowdfunding as a source of funding could be beneficial.

- Recommendation: Be savvy on how to use social media to build networks.

\subsection{Reflections on This Study}

\subsubsection{Methods and Conceptual Frameworks}

We stand-by our decision to use qualitative research methods and particular narratives as they allowed us to provide a think description from which we could better understand the SIEE's lived experiences. Using qualitative methods we were able to answer questions about experience, how the SIEEs developed meaning and understand their standpoint. As researchers, we became the instrument and the 'subjects' became our 'participants' (Denzin and Lincoln 1998). We have endeavored to provide a description of our procedures and a transparent explanation of our analysis and data management. We have also engaged in reflexivity, triangulation and worked closely with the participants themselves to ensure an accurate representation of their experience.

In future studies we will use self-determination theory as more central tenant from the outset; further developing theory from that stand point. In this study, we 
neglected to ask questions about the SIEE's retirement plans. This is an important aspect of better understanding how the SIEEs view their career and how connected they remain to Japan. How many SIEEs intend to return to Japan for retirement? How many utilize private pensions or do they rely on the Japanese state pension and what are the ramifications of that for the economy. In a similar vein, we should have addressed healthcare and the economic impact of any remittance of earnings to Japan. In future studies we will be sure to ask such questions.

\subsubsection{Future Research Directions}

We intend to continue researching in this field and will expand the study to explore Japanese SIEEs in South America and Africa. We are particularly interested in SIEEs in BRICS countries and we are also keen to move toward diaspora TE research among Japanese in Peru, where there are approximately 160,000 people of Japanese descent and Brazil, which has the largest Japanese population outside Japan.

Similarly, we have become more interested in non-Japanese SIEEs and other aspects of transnational entrepreneurship in Japan. Preliminary research by Birchley (2018) found that there is a strong case for Japan attracting foreign talent to maintain and develop society, counteract the declining birthrate and to provide an economic stimulus. There are many reasons to invest in Japan, particularly in light of new government initiatives such as the Invest Tokyo Project, the Tokyo One Stop Shop Business Establishment Center (TOSBEC) and business development centers around Japan. However, as of 2018, Birchley (2018) found that only a small number of expatriate entrepreneurs had taken advantage of the business support provided by the Tokyo government and that SIEEs attempting to enter Japanese markets need an awareness of traditional Japanese mental habits "which value intuition and experience... and the concept of socialization" which is a "quintessentially Japanese form of exchange behavior" (Glisby and Holden 2003). Knowledge of essential networks and brokers are of paramount importance to successfully establish a business in Japan. We hope that this book and especially, Chap. 2 can provide some cultural context for entrepreneurs considering entering Japan.

Finally, the increased number of foreign students and technical interns in Japan warrants an investigation into TE among that demographic of the population in Japan. Similarly, the increasing diaspora of Nepalese, Vietnamese and Indian business owners in Japan would also likely provide an interesting new research context. We feel that the field of TE and the study of entrepreneurs and the connection to Japan is a stimulating avenue of research. 


\subsection{Closing Remarks}

Japanese self-initiated expatriate entrepreneurs are exceptional individuals in that they not only exhibit a strong entrepreneurial mindset but also a global mindset that sets them apart from regular Japanese. They recognize opportunities around them, thanks to the experiences they have had since they were young. They were able to connect the dots and consolidate the experiences into a new and challenging stage of their career. The most profound finding was that they exhibit a high degree of self-efficacy, which we argue arises from their experiences. The Japanese SIEEs appear to be free thinkers who are secure in decision making (often based on their gut feeling). They make efforts to embed themselves in their new communities as they negotiate their multiple identities. In addition, they have a set of competencies that they continue to develop. The SIEEs are likely to encounter more uncontrollable risks while living and working abroad compared with ones who live and work in their home countries.

We encourage researchers to be interdisciplinary and to further explore the mindset and motivation of successful and unsuccessful SIEEs in a variety of contexts. We endeavor to further contribute to the field by extending this study to non-Japanese SIEEs in Japan and Japanese SIEEs in other emerging economies. To aspiring self-initiated expatriate entrepreneurs, we advocate for them to go abroad as soon as possible in their education or career and seek out a mentor or some form of guidance that will help him/her to connect the dots of their experience; consolidating it to develop a new mindset, greater knowledge, more extensive networks and increased motivation, while at the same time continually negotiating his/her identity.

In conclusion, the SIEE's primary needs of autonomy, belonging and competence are met. They have an intrinsic motivation and are able to self-regulate. They show a high degree of enjoyment and an inherent satisfaction in what they do as entrepreneurs. They engage in projects which are usefulness-driven in that they are related to their previous experience, their set of competencies and the needs of their new community. In addition, they have a value-driven attitude to their work; they, as often expressed through their career anchors, highlight that they are doing work which fits with their own deeply-held values and which excites and interests them. They fit Deci and Ryan's (1995) definition of an autonomous, motivated, individual who has intrinsic aspirations. They choose to be SIEEs with a strong sense of volition, energy and persistence. Who will be among the next generation of SIEE? 
Open Access This chapter is licensed under the terms of the Creative Commons Attribution-NonCommercial-NoDerivatives 4.0 International License (http://creativecommons. org/licenses/by-nc-nd/4.0/), which permits any noncommercial use, sharing, distribution and reproduction in any medium or format, as long as you give appropriate credit to the original author (s) and the source, provide a link to the Creative Commons license and indicate if you modified the licensed material. You do not have permission under this license to share adapted material derived from this chapter or parts of it.

The images or other third party material in this chapter are included in the chapter's Creative Commons license, unless indicated otherwise in a credit line to the material. If material is not included in the chapter's Creative Commons license and your intended use is not permitted by statutory regulation or exceeds the permitted use, you will need to obtain permission directly from the copyright holder.

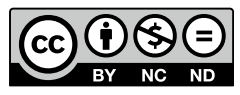

